\title{
A Dual Band Dual Polarization Slot Patch Antenna
}

\author{
Jianling Chen, Junhong Wang \\ Department of Electronics and Information Engineering, \\ Beijing Jiaotong University, \\ Beijing, China \\ 10111002@bjtu.edu.cn,wangjunh@bjtu.edu.cn
}

\author{
Kin-Fai Tong, Allann Al-Armaghany \\ Department of Electronic and Electrical Engineering, \\ University College London \\ Torrington Place, WC1E 7JE London, UK \\ k.tong@ucl.ac.uk, a.al-armaghany@ucl.ac.uk
}

\begin{abstract}
A dual band and dual polarization slot patch antenna for Global Positioning System (GPS) and wireless LAN network with the corresponding polarizations is proposed. An Lshaped slot and a small stub are utilized to excite the desirable right-hand circular polarization (RHCP) for GPS. Meanwhile the linearly polarized electromagnetic wave for Wi-Fi communications at $2.4 \mathrm{GHz}$ is contributed by an arc-shaped slot embedded circular patch. The multi-layered geometry and the capacitive feeding disk placed between the substrate layers enhance the operating bandwidths of the antenna. The achievable percentage bandwidths at the low and high bands are $6.4 \%$ and $7 \%$ respectively. The measured $3 \mathrm{~dB}$ axial ratio $(\mathrm{AR})$ bandwidth is $34 \mathrm{MHz}$, which covers the GPS L1 band.
\end{abstract}

Keywords-L-shaped slot, arc-shaped slot, circular patch antenna; GPS; Wi-Fi; dual-polarization, capacitive feeding

\section{INTRODUCTION}

Nowadays, antennas for wireless communications have to be compact and able to operate at several frequency bands simultaneously. The frequency bands normally include GPS systems, wireless LAN, and the $60 \mathrm{GHz}$ band for the soon coming $5 \mathrm{G}$ mobile communication systems [1-3]. Therefore, there is a demand for antennas that can operate in several frequency bands, in addition to the low profile, polarization alignment and low fabrication cost. A few multi-band antennas are reported for the GPS/WiMAX/WLAN systems [4-6], but polarization loss are expected for GPS reception. In [7-9], the single band circular polarization is excited by unsymmetrical U-slot or truncated corner U-slot patch antenna. In [10] a dual band and dual polarization antenna for GPS and $\mathrm{Wi}-\mathrm{Fi}$ application is introduced. A $90^{\circ}$ hybrid coupler chip is inserted to generate the two degenerative modes. Linear polarization in the Wi-Fi band is excited by the two symmetrical slots on the top radiator. Due to mounting process and extra DC biasing lines for the hybrid chip, the antenna fabrication is more complicated than a single feed antenna. The antenna performance is restricted.

In this paper, a single capacitive-fed patch antenna features a simple and compact structure is presented. This simple antenna can simultaneously support the GPS and Wi-Fi applications with the appropriate polarizations. For the GPS $1.575 \mathrm{GHz}$ band, it is designed to be RHCP, while linear polarization is achieved in the Wi-Fi $2.4 \mathrm{GHz}$ band.

\section{ANTENNA CONFIGURATION AND DESIGN}

Fig. 1 shows the top and side views of the proposed antenna geometry. The first layer is a single-side copper cladded Rogers Duriod 5880 substrate (thickness, $t_{l}=1.575 \mathrm{~mm}$, and relative permittivity, $\varepsilon_{r}=2.2$ ), the second layer is polystyrene foam $\left(t_{2}=7 \mathrm{~mm}, \varepsilon_{r}=1.06\right)$, and a copper ground plane is cladded on the bottom side of the second layer. On the top of the first layer, an arc-shaped slot (slot 1), an L-shape slot (slot 2), and a stub (stub 1) are inserted into a circular microstrip patch. On the top of the second layer, there is a circular feeding disc (diameter, $D_{2}=6.4 \mathrm{~mm}$ ) connected to the center pin of the SMA on the ground plane. The overall dimension of the antenna is $100 \times 100 \times 8.68 \mathrm{~mm}^{3}$. Slot 2 and the stub 1 are responsible to excite the orthogonal modes to generate the RHCP. Slot 1 radiating at $2.4 \mathrm{GHz}$ are embedded in the circular patch. The multi-layered geometry and the capacitive feeding disk placed between the substrate layers enhance the operating bandwidths of the antenna. By adjusting the dimension of the L-shape slot and the stub, the CP operating frequency and AR can be optimized. The detailed dimensions of the antenna are tabulated in Table 1.

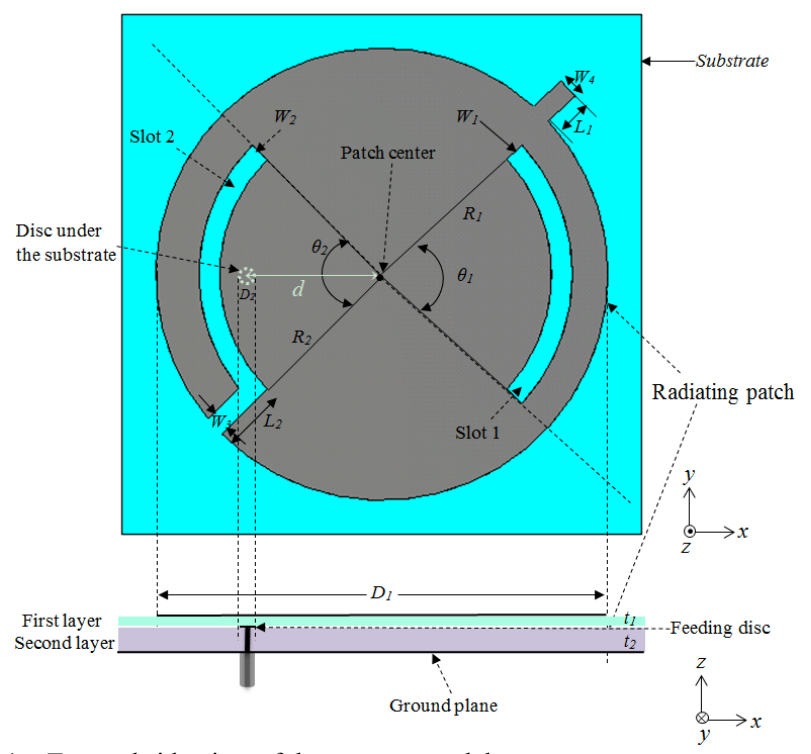

Fig. 1. Top and side view of the antenna model

TABLE I. DETAILED ANTENNA PARAMETERS (MM)

\begin{tabular}{|c|c|c|c|c|c|}
\hline $\begin{array}{c}\text { Diameter of the circular } \\
\text { patch, } D_{1}\end{array}$ & 87 & $\begin{array}{c}\text { Inner radius } \\
\text { of slot } 1, R_{1}\end{array}$ & 32.6 & $\begin{array}{c}\text { Inner radius of } \\
\text { slot 2, } R_{2}\end{array}$ & 31.2 \\
\hline $\begin{array}{c}\text { Subtended angle of the } \\
\text { slot } 1, \theta_{1}\end{array}$ & $85.32^{\circ}$ & $\begin{array}{c}\text { Subtended } \\
\text { angle of the } \\
\text { slot } 2, \theta_{2}\end{array}$ & $90^{\circ}$ & $\begin{array}{c}\text { Width of the } \\
\text { slot } 1, W_{1}\end{array}$ & 4.0 \\
\hline Width of the slot $2, W_{2}$ & 4.0 & $W_{3}$ & 4.0 & $\begin{array}{c}\text { Width of the } \\
\text { stub } W_{4}\end{array}$ & 4.0 \\
\hline $\begin{array}{c}\text { Distance between the } \\
\text { centers of the patch to } \\
\text { feeding disc, } d\end{array}$ & 26.0 & $\begin{array}{c}\text { Length of } \\
\text { the stub } L_{1}\end{array}$ & 6.5 & $L_{2}$ & 12.3 \\
\hline
\end{tabular}




\section{RESULTS}

The antenna parameters were optimized by using the commercial software package CST Microwave Studio in the simulation process. From Fig. 2, the two orthogonal modes for circular polarization can be observed in the low band around $1.575 \mathrm{GHz}$, while a single mode at $2.45 \mathrm{GHz}$ appear in the high band. The impedance bandwidth $\left(\left|\mathrm{S}_{11}\right|<-10 \mathrm{~dB}\right)$ is between 1.52 and $1.62 \mathrm{GHz}$, i.e. $6.4 \%$, for GPS and between 2.36 to $2.55 \mathrm{GHz}$, i.e. $7 \%$, for $\mathrm{Wi}-\mathrm{Fi}$ systems.

Fig. 3 shows the simulated axial ratio bandwidth of the antenna at the GPS band. The $3 \mathrm{~dB}$ AR bandwidth is about $2.1 \%$ from 1.562 to $1.596 \mathrm{GHz}$.

Fig. 4 and 5 show the simulated radiation patterns of the antenna at $1.575 \mathrm{GHz}$ and $2.45 \mathrm{GHz}$. The gains of the antenna at $1.575 \mathrm{GHz}$ is about $6.5 \mathrm{dBi}$, while it is about $7.8 \mathrm{dBi}$ at 2.45 $\mathrm{GHz}$.

In our further study, the frequency bands of the antenna can be optimized independently and simultaneously. The designed antenna has been fabricated and the measured results will be presented in the conference.

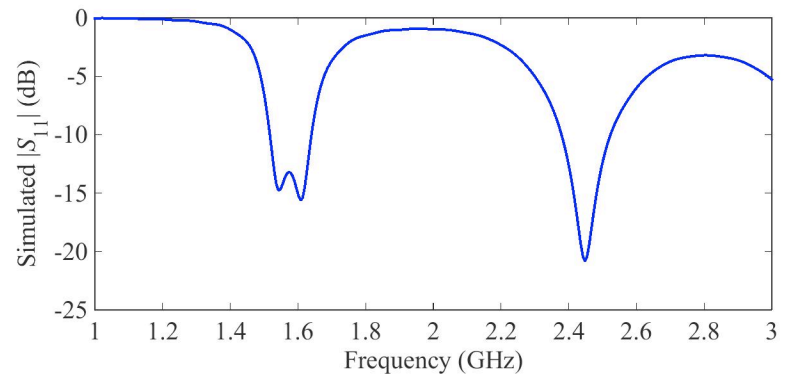

Fig. 2. $\mathrm{S}_{11}$ of the proposed antenn

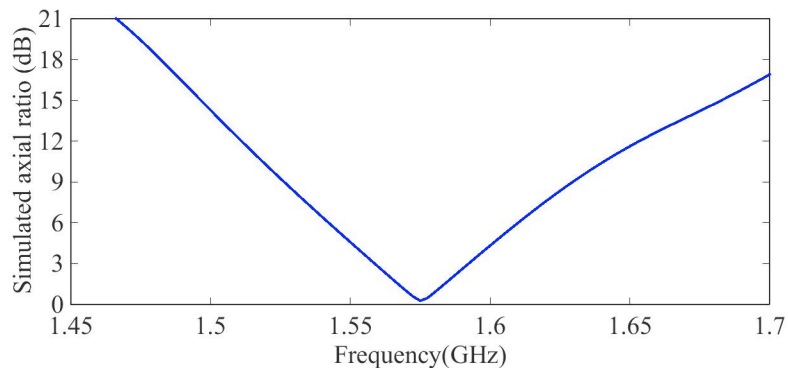

Fig. 3. Axial ratio of the proposed antenna

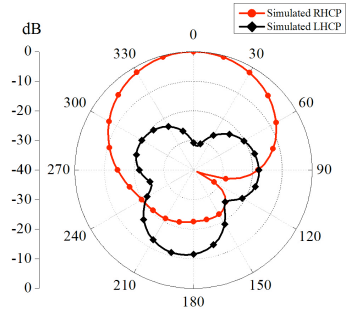

(a)

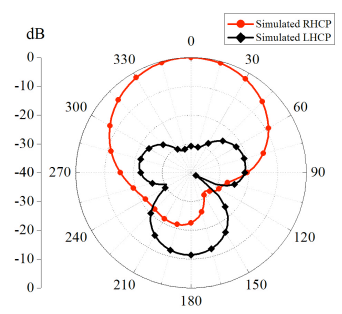

(b)
Fig. 4. Normalized radiation pattern at $1.575 \mathrm{GHz}$ in (a) $x z$-plane and (b) $y z$ plane (a)

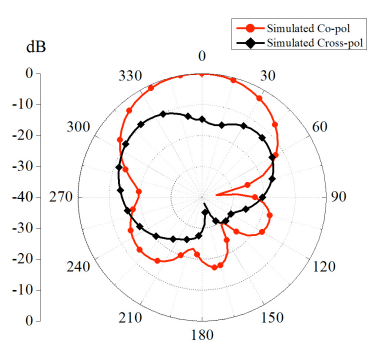

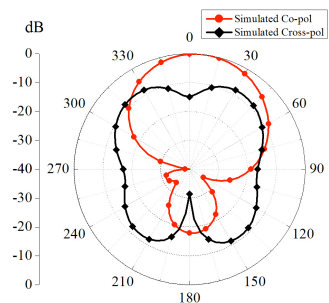

(b)
Fig. 5. Normalized radiation pattern at $2.45 \mathrm{GHz}$ in (a) $x z$-plane and (b) $y z$ plane

\section{CONCLUSIONS}

In this paper, we presented a single capacitive-fed technique to achieve a dual band antenna with desirable polarization at the specific band. Both low and high frequency bandwidths of the antenna meet the requirements of GPS and Wi-Fi standards.

\section{ACKNOWLEDGMENT}

This work is partially supported by the National Natural Science Foundation of China under Grant No.61331002, and by the National Program on Key Basic Research Project under Grant No.2013CB328903.

\section{REFERENCES}

[1] M.J. Ammann and Zhi Ning Chen, "Wideband monopole antennas for multi-band wireless systems", IEEE Antennas and Propag. Mag., vol.45, no.2, pp.146-150, April. 2003.

[2] Y. Li and K. M. Luk,"Low-Cost High-Gain and Broadband SubstrateIntegrated-Waveguide-Fed Patch Antenna Array for $60-\mathrm{GHz}$ Band", IEEE Trans. Antennas and Propag., vol.62, no.11, pp.5531-5538, Nov. 2014 .

[3] Y. Li and K. M. Luk, "60-GHz Substrate Integrated Waveguide Fed Cavity-Backed Aperture-Coupled Microstrip Patch Antenna Arrays", IEEE Trans. Antennas and Propag., vol.63, no.3, pp.1075-1085, March 2015

[4] Y.F. Cao, S.W.Cheung and T.I. Yuk, "A Multiband Slot Antenna for GPS/WiMAX/WLAN Systems," IEEE Trans. Antennas and Propag., vol.63, no.3, pp.952-958, March 2015.

[5] R. K. Raj, M. Joseph, B. Paul and P. Mohanan, "Compact planar multiband antenna for GPS, DCS, 2.4/5.8 GHz WLAN applications", Electron. Lett., vol. 41, no. 6, pp. 290-291, 17 March 2005.

[6] R. Zhang, H. Kim and H. Kim, "Triple-band ground radiation antenna for GPS, WiFi 2.4 and $5 \mathrm{GHz}$ band applications", Electron. Lett., vol. 51, no. 25, pp. 2082-2084, 12102015.

[7] W. Yang, J. Zhou, Z. Yu and L. Li, "Single-Fed Low Profile Broadband Circularly Polarized Stacked Patch Antenna," IEEE Trans. Antennas and Propag., vol.62, no.10, pp.5406-5410, Oct. 2014.

[8] M. Chen and C.-C. Chen, "A Compact Dual-Band GPS Antenna Design," IEEE Antennas Wireless Propag. Lett., vol. 12, pp. 245-248, 2013

[9] K. F. Tong and T. P. Wong, "Circularly Polarized U-Slot Antenna," IEEE Trans. Antennas and Propag., vol.55, no.8, pp.2382-2385, Aug. 2007

[10] J. Chen, K. Tong, A. Al-Armaghany and J.Wang, "A Dual Band Dual Polarization Slot Patch Antenna for GPS and Wi-Fi Applications," IEEE Antennas Wireless Propaga.Lett., vol. 15, no. , pp. 406-409, 2016.

[11] CST Microwave Studio user manual 